\title{
Research on supply chain architecture of logistics network platform based on blockchain technology
}

\author{
Lijuan Liu and Chao Li
}

Received: August 2, 2020. Revised: September 1, 2020. Accepted: September 2, 2020. Published: September 2, 2020.

\begin{abstract}
With the development of productivity, supply chain came into being. This study briefly introduced the blockchain and supply chain technology, constructed the blockchain-based supply chain logistics platform for managing the information of the supply chain, carried out the interface test on the logistics platform system in the laboratory, and made an analysis by taking XX flour factory in Sichuan province as an example. The laboratory interface test results showed that the system platform could be normally applied to the flour factory's supply chain management. The case analysis results showed that the supply chain that applied blockchain technology could effectively resist abnormal data modification to ensure the reliability of supply chain information and quickly trace the supply chain problems to improve the efficiency of supply chain management.
\end{abstract}

Keywords-Blockchain, logistics platform, supply chain, traceability.

\section{INTRODUCTION}

$\mathrm{I}$ $\mathrm{N}$ today's society with a high division of labor, the supply chain links suppliers, manufacturers, distributors, and users into an integrated network around core enterprises to ultimately achieve a stable win-win situation [1]. In the process of supply chain operation, unless pure information is sold, there must be the transportation of products, which forms logistics [2]. The supply chain can realize the transaction of goods without time and space constraints by using logistics. Although the supply chain organically integrates different trading members into a whole, forming a network chain linked with each other, which greatly expands productivity. But the supply chain also has hidden dangers, i.e., once a node in the supply chain makes mistakes on commodities, the whole supply chain may not collapse immediately, but it will cause adverse effects. Therefore, the source of commodities in the supply chain needs to be traced timely, i.e., the link which has problems in the supply chain needs to be searched [3]. In the traditional supply chain, although the node enterprises are closely linked with each other, due to different reasons, they actually form an information island, which makes it difficult to query the real information in the supply chain. In this study, blockchain technology was combined with supply chain to strengthen the reliability of supply chain information under the logistics

L. J. Liu is with the Neijiang Normal University, Neijiang, Sichuan 641112 , China (e-mail: 17j1i6@126.com).

C. Liu is with the Neijiang Normal University, Neijiang, Sichuan 641112, China. platform. Some relevant studies can be found in [16], [17], and [18]. Li et al. [4] and Yi [5] established supply chains using the blockchain; the supply chain established by the former can effectively concentrate the Heterogeneous logistics resources of different users, and the supply chain established by the latter can effectively ensure the individual privacy in the logistics system. Simulation experiments verified the effectiveness of the two supply chains. Christodoulou et al. [6] put forward a kind of smart contract to apply blockchain to logistics and illustrated by an example that the blockchain could effectively improve the transportation and tracking of products by logistics with the assistance of smart contract. This paper briefly introduced the blockchain and supply chain technology, constructed the supply chain logistics platform based on the blockchain for managing the information of the supply chain, carried out the interface test on the logistics platform system in the laboratory, and made an analysis by taking XX flour factory in Sichuan province, China, as an example. In the research process, the blockchain was regarded as a data storage device of the logistics system, and the authenticity of data storage was guaranteed by using blockchain decentralization. The problem faced by combining the logistics system and blockchain was how to ensure the reliability of data interaction between the logistics system and blockchain. Finally, the smart contract realized the data interaction between interfaces. Compared with the previous literature, this study combined the blockchain with the supply chain logistics platform through smart contracts and applied it to the supply chain system of wheat flour production. The main contribution of this study is to provide an effective reference for the logistics system to protect privacy in the logistic system and strengthen data authenticity.

\section{BLOCKCHAIN}

Blockchain is a distributed ledger database that relies on peer nodes and consensus algorithms in the network. Blockchain can also be seen as a state machine that constantly changes its state through transactions, and its evolution formula is as follows:

$\theta_{t+1} \equiv \mathrm{Y}\left(\theta_{t}, T\right)$

where $\theta_{t}$ represents the blockchain state at time t, $T$ is a transaction, and $\mathrm{Y}(\bullet)$ is a state transition function. After the transaction evolves for a period of time, the verified transactions 
are collected into the block, and the blocks are connected by the hash value. The state transition formula is as follows:

$$
\left\{\begin{array}{l}
\theta_{t+1} \equiv \Pi\left(\theta_{t}, B\right) \\
B \equiv\left(\left(T_{0}, T_{1}, \cdots\right), \cdots\right)
\end{array}\right.
$$

where $\Pi(\bullet)$ stands for block B based transaction transition function. Block B includes transaction $T$ and other data.

\begin{tabular}{|c|}
\hline Application layer \\
\hline Contract layer \\
\hline Incentive layer \\
\hline Consensus layer \\
\hline Network layer \\
\hline Data layer \\
\hline
\end{tabular}

Fig. 1 The hierarchical structure of blockchain

The hierarchical structure of blockchain is shown in Fig. 1. In the structure, the data layer is the bottom layer. The block encapsulates the data whose basic unit is transaction and uses cryptography such as hash algorithm and encryption algorithm to make unit data to form a linked list structure in the chronological order. There are two kinds of encryption algorithms: symmetric and asymmetric; the encryptor and decryptor of the former share the same key, while the latter has a private key and a public key. The derivation between them is unidirectional and irreversible.

Hash algorithm [7] is a compression mapping algorithm. Its principle is to compress the input data with different lengths into data with the same length through certain rules. After data compression by the hash algorithm, it is difficult to find the reverse law of the data. Moreover, there is a close relationship between the compressed data flag and the bytes of the source data. One of its characteristics is that the source data must be different if the hash values calculated by the same hash function are not the same, and the source data are highly likely to be the same or are likely to have the phenomenon of hash collision if the hashed values are the same. The hash collision can be reduced in the form of hash tabulation. Through the above characteristics, the hash algorithm can be used to encrypt the original data and verify whether the encrypted data are the original data.

The network layer is the main embodiment of blockchain's decentralization, and its encapsulated content includes network architecture, inter-block communication protocol and verification method. After a long time of development, the blockchain usually adopts peer to peer (P2P) network architecture [8]. In this network architecture, the participating computer nodes provide the same services through the topology structure, so there is no central service in the blockchain.

The consensus layer encapsulates all consensus mechanism algorithms of nodes in the blockchain. Due to the decentralization of blockchain, the "account books" of different nodes are highly dispersed. Therefore, it is necessary to select the most appropriate node to perform "bookkeeping right" through a consensus algorithm [9].

\section{LOGISTICS Platform SUPPLY CHAIN}

The food logistics supply chain is shown in Fig. 2, including raw material production link, food processing link, food storage link, food transportation link, and food sales link.

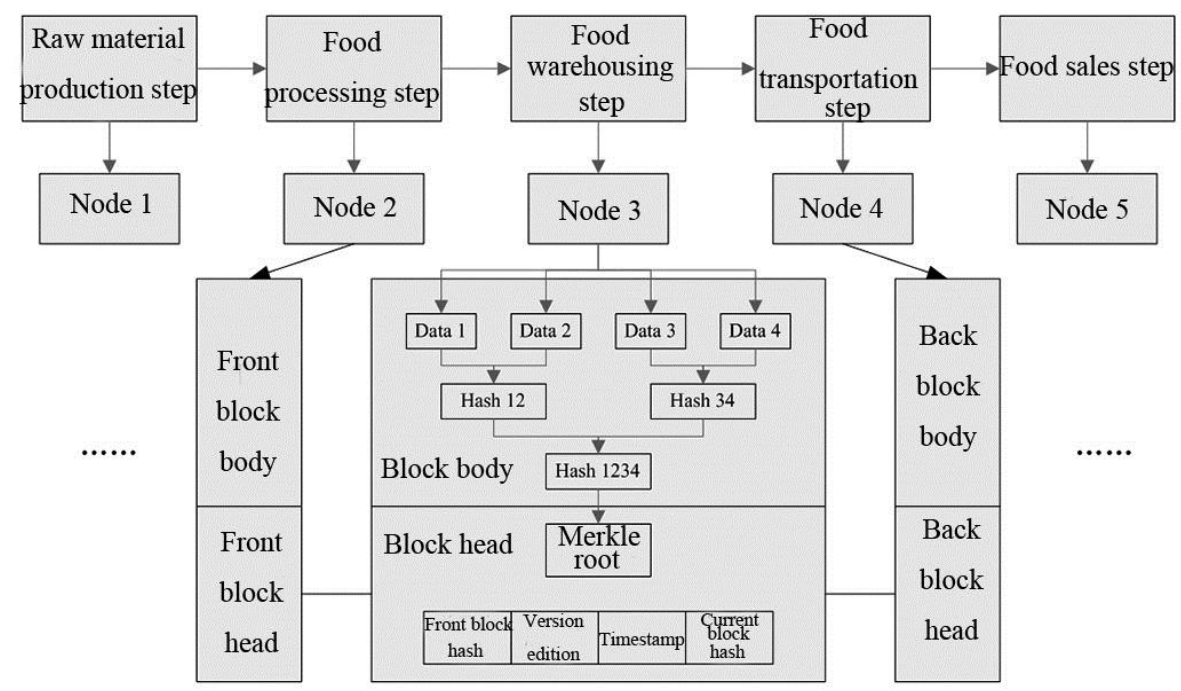

Fig. 2 The food logistics supply chain after combining with blockchain technology

With the advantages of distributed storage and consensus algorithm, blockchain can effectively guarantee data reliability in the supply chain [10]. The coupling form of supply chain and blockchain is shown in Fig. 2. The executing enterprise of each link in the supply chain can be regarded as a distributed independent node in the network. Each node corresponds to a 
block in the blockchain. The node enterprise in the corresponding link combines the data related to the logistics supply chain in pairs by using the hash algorithm to form a binary tree and finally converge to Merkle root [11], i.e., the root hash value. Then, the node's summary information is broadcast in the whole network, and other nodes in the P2P network use the consensus algorithm to verify the broadcast summary information. After the verification, the data is formally stored in the block and connected with the upper block to complete the operation of saving the node data into the blockchain. Similarly, node enterprises in other links process their data and store them in the blockchain. Blocks form a blockchain according to the order of node-link processing time.

\section{Supply Chain Logistics Platform Based ON BLOCKCHAIN}

The overall functional framework of the supply chain logistics platform based on blockchain is shown in Fig. 3. The platform includes blockchain cloud platform, user information management module, and order information management module. The blockchain cloud platform is the basis of the whole logistics platform, which provides blockchain services for the logistics supply chain and ensures the reliability of information transmission in the supply chain. It mainly includes the hash algorithm, smart contract, and consensus algorithm. The hash algorithm plays a role in encrypting and verifying data in the blockchain. A smart contract is the number implementation clause after negotiation between enterprise users participating in the platform, which is used for standardizing the data stored in the blockchain. The consensus algorithm is an algorithm used by all nodes to verify the authenticity and integrity of data after the data are obtained by the hash algorithm through recursion and broadcast to the whole network.

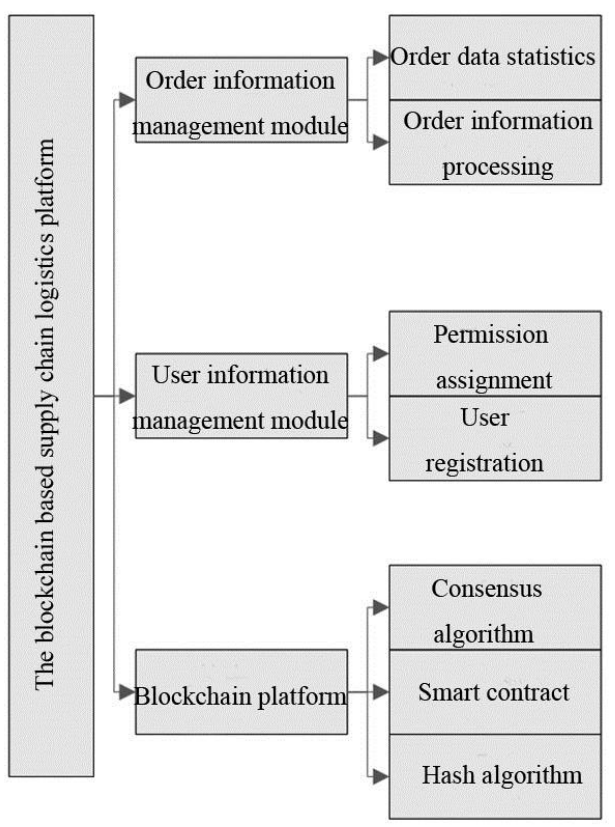

Fig. 3 The functional framework of supply chain logistics platform based on blockchain

The module of user information management is used in the platform for information management of enterprise users participating in the platform, mainly including user registration and permission allocation [12]. The former means registering account numbers for enterprise users in the platform, so that enterprises can participate in the supply chain in the platform; the latter means assigning different reading and writing permissions to different enterprise users in the platform. Although the nodes in the blockchain have equal status, they are still independent individuals. In the process of writing and browsing data information, they must have corresponding permissions to prevent irrelevant personnel from participating in it.

The module of order information management is used for managing the logistics information of the supply chain in the platform. It mainly includes two functions: order information processing and order data statistics. The former can set the generation method of logistics orders according to their own needs. In that function, the logistics order information can be collected through the information collection module or imported by enterprise users in the platform. Through a series of algorithms in the blockchain, the order information is generated and stored. The latter is to make statistics of all order data in the platform and arrange them in certain rules, and its main function is to provide order statistics and supporting data for the future development decision-making of participating enterprises.

Although the blockchain-based supply chain logistics platform mentioned above can effectively protect customer privacy and ensure the authenticity of stored data, there are still 
some limitations. First of all, blockchain technology has emerged not for a long time, and it is in the initial stage. In this study, the logistics system and blockchain need smart contract to realize data interaction. The smart contract is also in the test stage, which can not fully cover all project information of the platform and needs to be improved. Secondly, the blockchain used in this study comes from the Ethereum platform, which is more suitable for small-scale enterprise users and is difficult to deal with the big data processing of large-scale enterprises.

\section{CASE ANALysis}

\section{A. Subject Profile}

This study took XX flour factory in Sichuan province as an example. XX flour factory mainly sells different kinds of flour. It has many subsidiaries, and its subsidiaries are engaged in the production, processing, transportation, and sales of flour raw materials, i.e., the flour factory can realize the complete supply chain from wheat to flour sales by using its subsidiaries. Although the subsidiaries of the flour factory operate independently, they still belong to the same flour factory, thus realizing a flour factory with a complete supply chain. Moreover, due to the fact that all the subsidiaries are under the same factory, relatively complete information can be obtained by investigating the flour factory headquarter. The supply chain, which is composed of the subsidiaries of the factory, effectively improves the production and sales efficiency of the flour factory. However, due to the independence of node enterprises, the quality control of products in each link in the circulation process of flour in the supply chain is carried out by the node enterprise in the link independently, which reduces the reviewing force in each link. Whether it is operation error or motivation by profit, it will eventually cause problems on the quality of flour. Besides, the supply chain improves the circulation efficiency, which means the increase of product circulation data and greatly increases the difficulty of locating the link which has problems in the supply chain. In this study, the supply chain logistics platform was established by blockchain coupled with supply chain to manage the logistics information of flour in the supply chain and realize the precise positioning of quality control.

\section{B. Overview of Supply Chain Logistics Platform System}

In this study, the blockchain-based supply chain logistics platform system includes application web page, server, and blockchain network platform. The application web page of the system platform was written by HTML and Java language [13]. The server function was realized by WebService technology, and the blockchain network platform function of the system was provided by the Hyperledger Fabric blockchain platform. The Practical Byzantine Fault Tolerance (PBFT) algorithm was used as the consensus algorithm in the blockchain.

\section{System Testing}

The supply chain logistics platform was built by using blockchain, and the quality of the flour factory's supply chain was monitored. To verify the effectiveness of the platform system for supply chain quality control, the system test was carried out. The test was divided into laboratory interface test and practical application test.

(1) Laboratory interface test

Interface test is a unit test, which is used to check whether the function of a system can operate normally. This study used the 360 browser to simulate the client in the system platform. The test content includes the input of supply chain information and the query of supply chain information. The test process of the former is as follows: (1) enter the supply chain information input page; (2) click "information input"; (3) input the data information of the corresponding link of the supply chain and submit it; (4) wait for the feedback from the system. The test process of the latter is as follows: (1) enter the supply chain information query page; (2) select the supply chain query target and scope; (3) click "information query"; (4) wait for the system feedback.

(2) Practical application test

The supply chain logistics platform was applied to the supply chain of the XX flour factory. In this study, the flow after the supply chain of the flour factory was combined with blockchain is as follows: (1) the subsidiary company receives the wheat, carries out the quality inspection, and uploads the quality inspection results to the logistics platform; (2) the wheat quality inspection data is formally stored in the database of the platform after being verified by the intelligent contract and consensus algorithm of the blockchain [14]; (3) in the links of processing, storage, transportation, and sales, in addition to executing the works of corresponding links mentioned above, quality inspection of products is also required, the quality inspection data and other relevant data are uploaded to the logistics platform and formally stored in the platform database after being verified by the intelligent contract and consensus algorithm of the blockchain.

The test content included the resistance of the system platform to the falsified supply chain information [15] and the capability of the system platform in locating and tracing the link that has problems in the supply chain. The testing method for the resistance of the system platform to the falsified supply chain is as follows. The original processing information was modified in the processing link of the supply chain and uploaded to the blockchain, and then whether the falsified information in the last link was stored in the database was queried in the following supply chain link.

The test method for the capability of the system platform in locating and tracing the link which has problems is as follows. The supply chain batch number was inquired in the supply chain query interface of the system platform, and then the query button was clicked. After the query results were displayed, the query results were browsed and compared with the field survey results of the flour factory.

To further verify the information protection performance of the blockchain-based supply chain logistics platform, it was compared with another logistics platform system without blockchain participation. In the logistics platform without 
blockchain participation, the servers of different links were basically independent. Finally, when querying the supply chain information in the logistics platform of the master server, the master server needed to obtain data through the communication protocols with the servers in different links. The test method of the supply chain logistics platform without blockchain was the same as the above test method.

\section{Test Results}

Before applying the supply chain logistics platform for monitoring the supply chain of the flour factory, the interface test was carried out in a laboratory to test functions of supply chain information input and supply chain information query of the system platform. The test results are shown in Table I. In the test flow of the supply chain information input, after entering the information input page and clicking the button of "input", an information input box will appear; after inputting the information in the input box and submitting, a prompt box will appear. In the test flow of the supply chain information query, after entering the information query page, the target and range are queried; after clicking the bottom of "query", a prompt box will appear, and the query results will be displayed. Therefore, the system platform could be used in the supply chain monitoring of the flour factory.

Table I Laboratory interface test results

\begin{tabular}{|l|l|l|l|}
\hline Testing process & $\begin{array}{l}\text { Supply chain information } \\
\text { input test }\end{array}$ & Testing process & $\begin{array}{l}\text { Supply chain information } \\
\text { query test }\end{array}$ \\
\hline $\begin{array}{l}\text { 1)Does it successfully } \\
\text { enter the information } \\
\text { input page? }\end{array}$ & Yes & $\begin{array}{l}\text { 1)Whether enter the } \\
\text { information query page } \\
\text { successfully? }\end{array}$ & Yes \\
\hline $\begin{array}{l}\text { (2)hether the } \\
\text { information input box } \\
\text { pops out after clicking } \\
\text { the information input } \\
\text { button? }\end{array}$ & Yes & $\begin{array}{l}\text { 2) Can the query target and } \\
\text { range be selected } \\
\text { normally? }\end{array}$ & Yes \\
\hline $\begin{array}{l}\text { 3) Is the information } \\
\text { submitted successfully } \\
\text { after input? }\end{array}$ & Yes & $\begin{array}{l}\text { 3)After clicking the } \\
\text { information query button, } \\
\text { whether a prompt box pops } \\
\text { out? }\end{array}$ & Yes \\
\hline $\begin{array}{l}\text { 4)Whether the prompt } \\
\text { box of successful } \\
\text { information submission } \\
\text { pops out? }\end{array}$ & Yes & $\begin{array}{l}\text { 4)is the query result } \\
\text { displayed successfully? }\end{array}$ & Yes \\
\hline
\end{tabular}

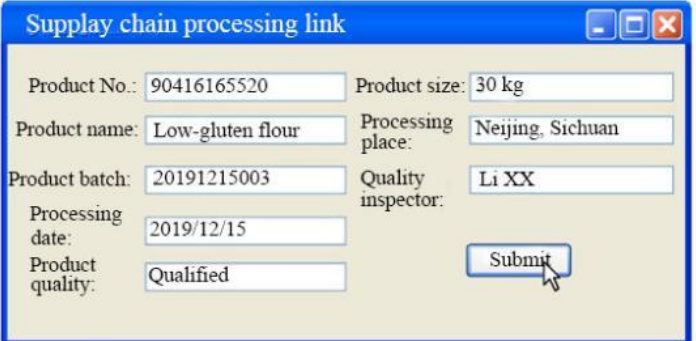

(1) The supply chain processing link input interface of two logistics platforms

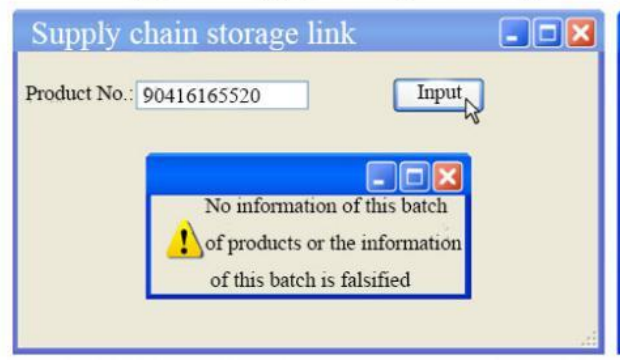

(2) The input interface of warehousing link in the blockchain based logistics platform

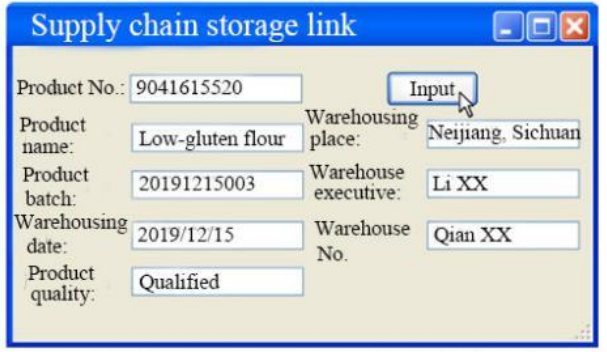

(3) The input interface of warehousing link in the logistics platform without blockchain
mation of the two system platforms
The combination of the supply chain logistics platform and blockchain technology can prevent the supply chain information from being falsified. The test results are shown in Fig. 4. Fig. 4(1) is the information input page of the two 
logistics platforms, which displays the input information of the processing step, but the product quality was falsified. In the original processing link, the low-gluten flour of this batch was evaluated as unqualified, but it was modified to "qualified" in this test, and the rest of the information was not modified.

After clicking "submit", the information of the last step was queried in the following warehousing step. Fig. 4(2) is the input page of the system designed in this study. A prompt box rather than an information interface appeared, and the content of the prompt box was "no information of this batch of products or the information of this batch is falsified". Moreover, when the system platform queried the complete supply chain logistics information of the batch of products, the processing information among the supply chain information was still displayed as unqualified.

However, in the logistics platform without blockchain, after entering the interface of the warehousing link of the supply chain, after inputting the product number, as shown in Fig. 4(3), the interface normally fed back the warehouse data input interface, and the information was input normally and submitted. Moreover, when the system platform queried the complete supply chain logistics information of the batch, the processing information has been falsified.

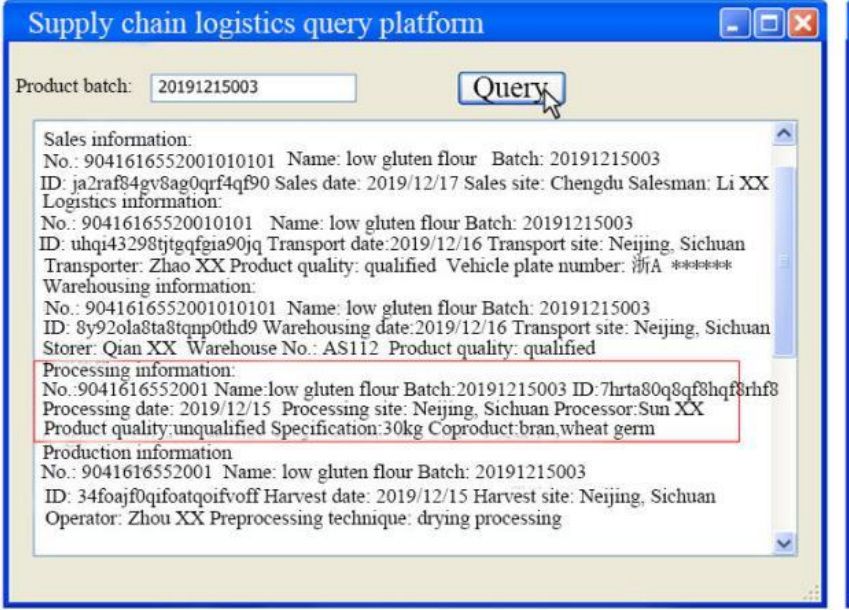

(1) The supply chain query result of the blockchain based logistics platform

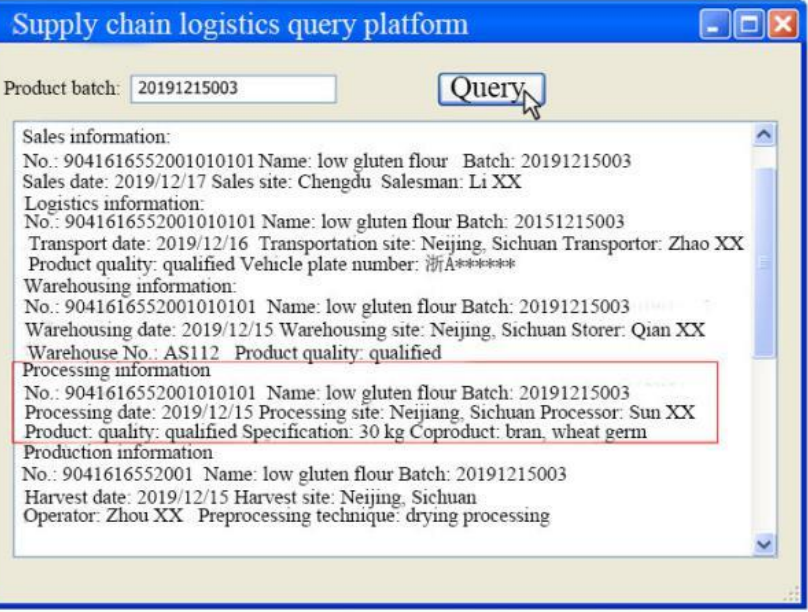

(2) The supply chain query result of the logistics platform without blockchain

Fig. 5 The logistics information query results of the supply chain logistics platforms

The product batch to be queried was input into the supply chain information query interface of the supply chain logistics platform proposed in this study. The query batch of this test was the same as the product batch used in the previous resistance experiment, i.e., "20191215003". Moreover, querying the supply chain information in the query interface was carried out after the experiment of modifying the processing link. The query results are shown in Fig. 5. Fig. 5 shows that the quality problem of this batch is attributed to the processing link. Rapid positioning of links that have problems in the supply chain can help to reduce the impact of quality problems and target the accountability of relevant personnel to improve management efficiency.

In Fig. 5(2), the logistics platform without blockchain could also query the complete supply chain information, but could not trace and position the link which induced the quality problem, and moreover, the quality information in the processing link has been falsified as qualified so that the supply chain was found having no problems after query. The comparative experiment of the two platform systems further verified that supply chain combined with blockchain could protect information security well and trace the supply chain to position the link that has problems rapidly.

\section{DISCUSSION}

The emergence of supply chain makes the division of social production more and more significant, but also makes the quality control more difficult. Links in the supply chain are continuous. Once a link has problems, the following links will also have problems. However, each link in the supply chain is somewhat independent. In the traditional supply chain logistics systems, information is not exchanged; therefore, once the information is falsified, other links can not verify the authenticity of the falsified information. The decentralization and consensus algorithm of the blockchain makes it impossible to falsify the data stored in it. This study introduced the blockchain into the supply chain logistics platform, which made the supply chain logistics platform have the advantages of blockchain and enhanced the authenticity of the data.

The following test also verified the protective effect of the blockchain-based supply chain logistics platform based on information data. The interface test verified that the system could work normally. After that, the comparison with the traditional supply chain logistics platform also showed that the blockchain-based logistics platform could effectively prevent information tampering. The reason was that every supply chain link had a unique ID, which was the traceability code of the 
corresponding supply chain link. The traceability code is a summary code obtained by calculating the data information in the supply chain with the Hash algorithm. In addition to the current block, it will also be transmitted to the next block and broadcast to the whole blockchain. Only after it is verified by the consensus mechanism can it be formally stored in the block. Therefore, it was seen from the query results in Fig. 5 and the operations in Fig. 4 that even if the processing links in the supply chain have been artificially modified, the final query results have not changed, and the product quality in the processing link was still unqualified, which further verified that the combination of the supply chain and blockchain could effectively resist illegal information modification. Moreover, due to the use of the blockchain, the integrity and authenticity of the supply chain information were ensured. Once the product quality has problems, the corresponding information can be obtained by retrieving the corresponding keywords in the supply chain information, so as to quickly query the link that had problems. When the corresponding unqualified keywords were retrieved, the corresponding information was browsed to locate the link that has problems rapidly.

\section{CONCLUSION}

This paper briefly introduced the blockchain and supply chain technology, then constructed a supply chain logistics platform based on blockchain for managing the supply chain information, carried out the interface test of the logistics platform system in a laboratory, and took XX flour factory in Sichuan province as an example for analysis. The results are as follows: (1) the interface test results in the laboratory showed that the constructed system platform could be applied to the supply chain management of the flour factory; (2) after the artificial information modification of the processing link in the supply chain, it was impossible to query the supply chain information of the batch and input the storage information normally in the following storage link; (3) the query results of the supply chain logistics information could quickly locate the link which has problems in the supply chain, and moreover, the query results also showed that the information would not be stored in the blockchain due to the inconsistency of the modified traceability code even if the information in the supply chain link was modified artificially, which effectively ensured the reliability of the supply chain information.

\section{REFERENCES}

[1] B. Suzuki, T. Taylor, and G. Marchant, "Blockchain: How It Will Change Your Legal Practice," Comput. Internet Lawyer, vol. 35, pp. 5-9, 2018.

[2] S. Ahmed, and N. Ten Broek, "Blockchain could boost food security," Nature, vol. 550, no. 7674, pp. 43-43, Oct. 2017.

[3] O. Hueber, "The blockchain and the sidechain innovations for the electronic commerce beyond the Bitcoin's framework," Int. J. Transit. Innov. Syst., vol. 6, no. 1, pp. 88-102, Jan. 2018.

[4] M. Li, L. Shen, and G. Q. Huang, "Blockchain-enabled workflow operating system for logistics resources sharing in E-commerce logistics real estate service," Comput. Ind. Eng., vol. 135, no. SEP., pp. 950-969, Jul. 2019.
[5] H. Yi, "A secure logistics model based on blockchain," Enterp. Inf. Syst., no. 4, pp. 1-17, Dec. 2019

[6] P. Christodoulou, K. Christodoulou, and A. Andreou, "A Decentralized Application for Logistics: Using Blockchain in Real-World Applications," Cyprus Rev., vol. 30, no. 2, pp. 181-193, Oct. 2018.

[7] A. Bhardwaj, V. Avasthi, and H. Sastry, "Ransomware: A Rising Threat of new age Digital Extortion," Ind. J. Sci. Tech., vol. 9, no. 14, Dec. 2015.

[8] S. Surjandy, M. Widjaja, A. N. Hidayanto, and H. Prabowo, "The latest adoption blockchain technology in supply chain management: a systematic literature review," ICIC Express Lett., vol. 13, no. 10, pp. 913-920, Oct. 2019

[9] M. Dobrovnik, D. Herold, E. Fürst, and S. Kummer, "Blockchain for and in Logistics: What to Adopt and Where to Start," Logistics, vol. 2, no. 3, pp. 18-, Sept. 2018.

[10] M. Felder, and M. Kuperberg, "Blockchain @ Deutsche Bahn: Anwendungen für Mobility \& Logistics," Dersenbahningenieur, vol. 69, no. 2, pp. 14-16, 2018.

[11] M. Li, S. Shao, Q. Ye, G. Xu, and G. Q. Huang, "Blockchain-enabled logistics finance execution platform for capital-constrained E-commerce retail," Robot. Cim-Int. Manuf., vol. 65, pp. 101962, Oct. 2020.

[12] P. Dangayach, "Pharmaceutical supply chain tracking system based on blockchain technology and radio frequency identification tags," Int. J. Busin. Res., vol. 19, no. 4, pp. 37-44, Dec. 2019.

[13] L. Koh, A. Dolgui, and J. Sarkis, "Blockchain in transport and logistics paradigms and transitions," Int. J. Prod. Res., vol. 58, no. 7, pp. 2054-2062, Apr. 2020.

[14] S. S. Kamble, A. Gunasekaran, M. Goswami, and J. Manda, "A systematic perspective on the applications of big data analytics in healthcare management," Int. J. Healthcare Manag., vol. 12, no. 3, pp. 226-240, Oct. 2019

[15] Y. Ziegler, V. Uli, F. Keller, and A. Kramer, "The Impact of Blockchain Networks on Logistics: an Update," in 38. mednarodna konferenca o razvoju organizacijskih znanosti, 2019.

[16] Aneta Zem?nkov?, "Artificial intelligence and blockchain in audit and accounting: literature review", WSEAS Trans. Busin. Econ., vol. 16, pp. 568-581, 2019.

[17] Silva ECE, Correia A, Braga A, Braga V, "A multinomial logistics model for perceptions on entrepreneurship," WSEAS Trans. Busin. Econ., vol. 15, pp. 1-8, 2018.

[18] Utomo SD, Machmuddah Z, Pamungkas ID, "The effect of auditor switching and managerial ownership on fraudulent financial statement," WSEAS Trans. Busin. Econ., Vol. 16, pp. 306-315, 2018.

Lijuan Liu, born in 1975, has received the master's degree from University of Electronic Science and Technology of China. She is an associate professor in Neijiang Normal University. She is interested in database technology.

Chao Li, born in 1991, has received the master's degree from Zhengzhou University. She is a teaching assistant in Neijiang Normal University. She is interested in supply chain management.

\section{Creative Commons Attribution License 4.0 (Attribution 4.0 International, CC BY 4.0)}

This article is published under the terms of the Creative Commons Attribution License 4.0 https://creativecommons.org/licenses/by/4.0/deed.en_US 